\title{
Relationship between health-related quality of life and respiratory health status among coal-based sponge iron plant workers in Barjora, India
}

\author{
Mousumi Biswas $^{1}$ (D) $\cdot$ Kaushik Chattopadhyay $^{2}$
}

Received: 22 February 2017 / Accepted: 23 October 2017 / Published online: 6 November 2017

(C) The Author(s) 2017. This article is an open access publication, corrected publication January/2018

\begin{abstract}
Background Many coal-based sponge iron plant workers have poor health-related quality of life in general, and specifically a poor respiratory health status. However, the relationship between their health-related quality of life and respiratory health status is unknown.

Aim This study investigated the relationship between healthrelated quality of life, measured using the EuroQol-5D (EQ5D), and respiratory health status, measured using the St. George's Respiratory Questionnaire (SGRQ), among coal-based sponge iron plant workers in Barjora, India.

Method A cross-sectional study was conducted among coalbased sponge iron plant workers in Barjora, and complete data were available on 252 participants. Spearman's rank correlation coefficients were reported to show the strength of relationship between health-related quality of life and respiratory health status.

Results and conclusion Significant correlations were found between all EQ5D dimensions/visual analogue scale (VAS) and all SGRQ scores except between EQ5D-VAS and SGRQ-activity. A range of correlations was found. They were moderate between EQ5D-anxiety/depression and SGRQsymptom, EQ5D-VAS and SGRQ-symptom, and EQ5D-anxiety/depression and SGRQ-total, but weak between all the other factors.
\end{abstract}

Mousumi Biswas

mousumi.biswas@york.ac.uk

1 Centre for Reviews and Dissemination, University of York, York YO10 4DU, UK

2 Division of Epidemiology and Public Health, School of Medicine, The University of Nottingham, Nottingham, UK
Keywords Health-related quality of life $\cdot$ Respiratory health status $\cdot$ EQ5D $\cdot$ SGRQ

\section{Background}

During the past decade, the number of coal-based sponge iron plants has grown rapidly in the Barjora block of Bankura district, a deprived district in West Bengal, India [Centre for Science and Environment (CSE) 2011]. These factories are categorised as red industries (i.e. highly polluted industries) with the major pollutants including particulate matters and gaseous pollutants, the toxic effects of which are often rapid (Centre for Science and Environment (CSE) 2011; Cerana Foundation 2006; Chatterjee 2011; Patra et al. 2012). Prolonged exposure to such pollutants leads to obstructive lung disease such as asthma or chronic obstructive respiratory disease (COPD) (Gizaw et al. 2016; Lai and Christiani 2013). Coal-based sponge iron plant workers are not only at risk of developing respiratory diseases, but many also have some form of respiratory disease (Chattopadhyay 2016). The unhealthy working environment is evidently a significant predictor of health-related quality of life (Taghavi et al. 2014). Coalbased sponge iron plant workers have poor health-related quality of life and respiratory health status (Chattopadhyay et al. 2014; Chattopadhyay et al. 2015). Poor health-related quality of life and respiratory health status place a burden on the individual, family, community and health services, and are thus of major public health importance (Fayers and Machin 2007; Institute of Medicine 2001; Jones 1995; World Health Organization (WHO) 2001).

A single intervention can only be developed, evaluated and implemented to improve the health-related quality of life of people as well as their respiratory health status if they are found to be related. Previous studies have shown 
a significant association between psychological factors (such as anxiety and depression) and respiratory health status in people with respiratory diseases (Balcells et al. 2010; Dyer et al. 1999). Psychological components are an important part of the health-related quality of life (Fayers and Machin 2007). Some research has been conducted to explore the correlation between health-related quality of life and the respiratory health status of patients with respiratory diseases such as COPD or idiopathic pulmonary fibrosis (IPF) (Chen et al. 2014; Starkie et al. 2011; Wilke et al. 2012) and found significant relationships. Studies have also been conducted in different countries to explore the health-related quality of life and respiratory health status in various industrial workers, but the relationship between their health-related quality of life and respiratory health status has never been explored (Rachiotis et al. 2006; Zhu et al. 2012). Similarly, the relationship between the health-related quality of life and respiratory health status among coal-based sponge iron factory workers is unknown. Hence, the aim of this study was to investigate the relationship between health-related quality of life [measured using the EuroQol-5D (EQ5D)] and respiratory health status [measured using the St. George's Respiratory Questionnaire (SGRQ)] among coal-based sponge iron plant workers in Barjora.

\section{Methods}

\section{Study}

This article presents a new analysis of a study conducted among coal-based sponge iron plant workers in Barjora (Bankura district, West Bengal, India) in May and June 2013 to assess their health-related quality of life and respiratory health status (Chattopadhyay et al. 2014; Chattopadhyay et al. 2015). We analysed the complete data available on 252 participants to report the relationship between health-related quality of life and respiratory health status. Ethics approval was received from the Barjora Block Development Office Committee and was based on the Indian Council of Medical Research Ethical Guidelines for Biomedical Research on Human Participants, 2006 [Indian Council of Medical Research (ICMR) 2006].

\section{Description of EQ5D}

Participants' health-related quality of life was assessed using the EQ5D questionnaire (Rabin et al. ; The EuroQol Group. 1990). The EQ5D assesses the overall functioning and wellbeing of individuals in terms of their mobility, self-care, usual activities, pain or discomfort, and anxiety or depression. In addition, participants rate their current health using a visual analogue scale (VAS) on a 0 (death or worst possible health) to 100 (best possible health) scale.

\section{Description of SGRQ}

Participants' respiratory health status was assessed using the St. George's Respiratory Questionnaire (SGRQ). The SGRQ has 50 items with 76 weighted responses (Jones et al. 1991) and provides three domain scores (symptoms, activity and impact) and a total score, ranging from 0 (optimal) to 100 points (worst).

\section{Statistical analysis}

The five dimensions of the EQ5D were described in terms of percentages. The EQ5D-VAS, all three SGRQ domains and SGRQ total scores were described as means and standard deviations (SD). Only participants who completed all aspects of these two questionnaires were included in the analyses. Spearman's rank correlation coefficients $\left(r_{s}\right)$ were reported to show the relationship between EQ5D and SGRQ. The strength of the relationship was defined as strong $\left(r_{s}>\right.$ $0.701)$, moderate $\left(r_{s}=0.301\right.$ to 0.700$)$ or weak $\left(r_{s}<0.300\right)$. Data analyses were done using Stata 14 for Windows software (StataCorp 2015).

\section{Results}

All 252 participants were males, with a mean age of 35.4 years (SD 8.2). The majority of the participants were manual workers $(78 \%)$ and literate $(88 \%)$.

Percentages for the five EQ5D dimensions are shown in Fig. 1. In the mobility dimension, $77 \%$ of participants responded that they had no problem with mobility, and 23\% responded that they had some problem (14\% slight, $6 \%$ moderate and $2 \%$ severe with $0.4 \%$ unable to walk). In the selfcare dimension, most of the participants had no problem taking self-care (95\%) and only a few participants (5\%) had some problems taking self-care. In the usual activities dimension, the majority of the participants responded that they had no problem performing usual activities (89\%) and only $11 \%$ responded that they had some problems performing usual activities (9\% slight, $1 \%$ moderate and $1 \%$ severe). In the pain/ discomfort dimension, $61 \%$ of participants reported that they had some form of pain or discomfort (26\% slight, $8 \%$ moderate, $4 \%$ severe and $2 \%$ extreme). In the anxiety/depression dimension, almost half of the participants reported slight to extreme anxiety or depression (31\% slight, $8 \%$ moderate, $6 \%$ severe and $0.4 \%$ extreme).

For the EQ5D-VAS, the three SGRQ domain scores and the SGRQ total score, means and SDs are presented in Table 1. The mean EQ5D-VAS score was 69.9 (SD 18.6). 
Fig. 1 Five dimensions of EQ5D - percentages
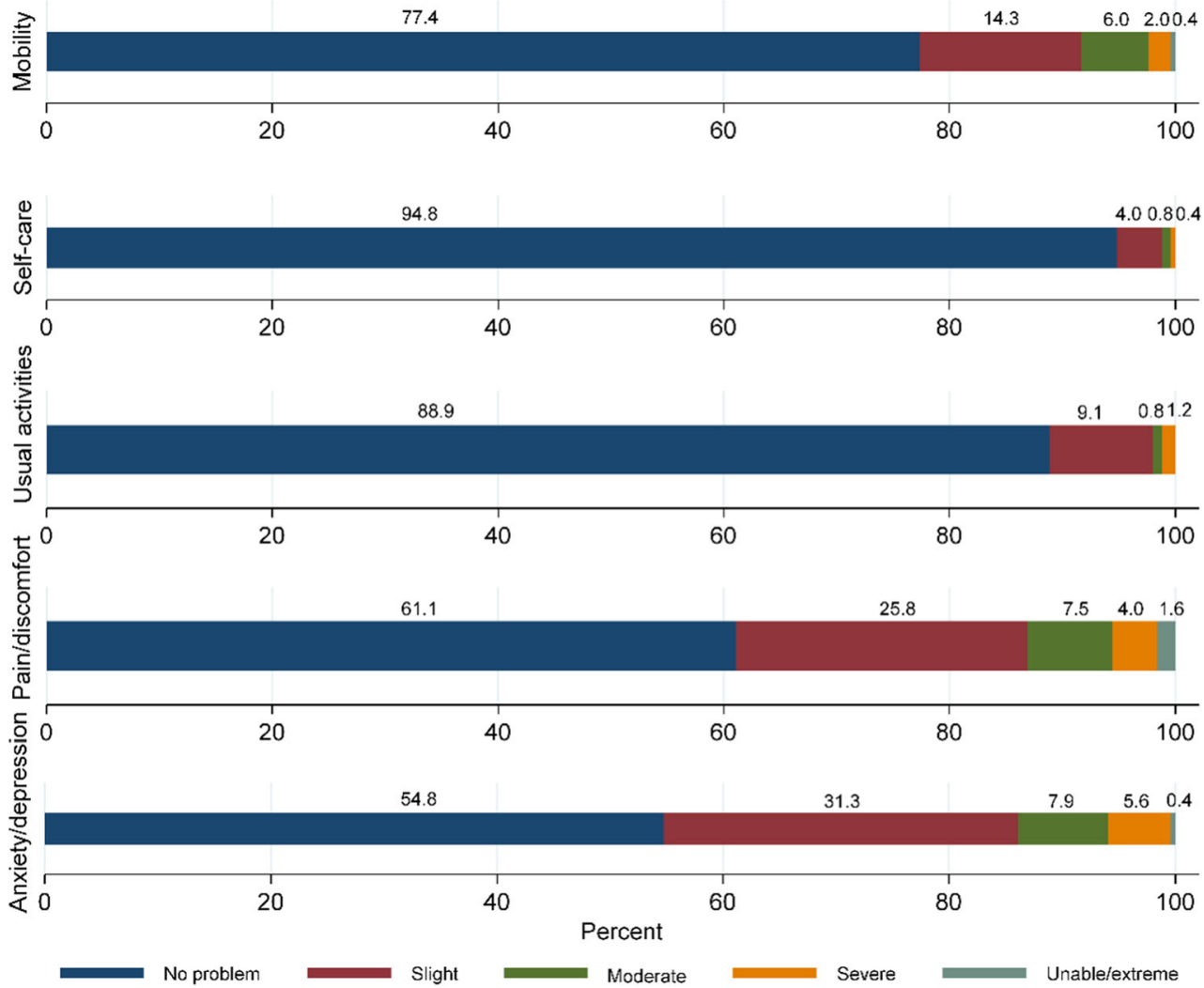

The mean scores in the SGRQ domains were 9.9 for SGRQsymptom (SD 18.4), 9.6 for SGRQ-activity (SD 19.0) and 5.9 for SGRQ-impact (SD 13.8). The mean total SGRQ score was 7.7 (SD 14.6).

Spearman's rank correlation coefficients $\left(r_{s}\right)$ are presented in Table 2 to show the relationship between EQ5D and SGRQ. Correlations between all EQ5D dimensions/VAS and all SGRQ scores were significant except between EQ5D-VAS and SGRQ-activity. A negative correlation was observed between the EQ5D-VAS and all SGRQ scores with $r_{s}$ ranging between -0.196 and -0.349 . The strength of these correlations varied. It was moderate between EQ5D-anxiety/depression and SGRQ-symptom $\left(r_{s}=0.440\right)$, EQ5D-VAS and SGRQsymptom $\left(r_{s}=-0.349\right)$, and EQ5D-anxiety/depression and SGRQ-total $\left(r_{s}=0.341\right)$. All other factors had a weak relationship with $r_{s}$ ranging between 0.133 and 0.291 .

\section{Table 1 EQ5D-VAS} and SGRQ scores - means and SDs

\begin{tabular}{lr}
\hline Domains & Mean (SD) \\
\hline EQ5D-VAS & $69.9(18.6)$ \\
SGRQ-symptoms & $9.9(18.4)$ \\
SGRQ-activity & $9.6(19.0)$ \\
SGRQ-impact & $5.9(13.8)$ \\
SGRQ-total & $7.7(14.6)$ \\
\hline
\end{tabular}

$S D$ Standard deviation

\section{Discussion}

Significant correlations were found between all EQ5D dimensions/VAS and all SGRQ scores except between EQ5D-VAS and SGRQ-activity. A range of correlations was found: moderate between EQ5D-anxiety/depression and SGRQ-symptom, EQ5D-VAS and SGRQ-symptom, and EQ5D-anxiety/depression and SGRQ-total, but weak between all the other factors. A statistically significant negative relationship was observed between EQ5D-VAS and the SGRQ domains (except SGRQ-activity). Perhaps this observed negative relationship was the result of how these two measurement tools were scored. A higher value in the EQ5D-VAS reflected a better health-related quality of life, whereas a lower value in the SGRQ reflected a better respiratory health status (Jones et al. 1991; The EuroQol Group. 1990).

Our study showed a weak correlation between EQ5DVAS and the SGRQ-total score (Spearman's rank correlation coefficient $-0.236, p$-value $<0.001$ ). It included participants who were at risk of developing respiratory diseases as well as those who already had some form of a respiratory disease (Chattopadhyay 2016). However, a previous study conducted among COPD patients in Hong Kong showed a moderate correlation between EQ5D-VAS and the SGRQ-total score (Pearson correlation coefficient -0.437 , p-value $<0.001$ ) (Chen et al. 
Table 2 Relationship between EQ5D dimensions and EQ5DVAS and SGRQ domains

\begin{tabular}{lllll}
\hline & $\begin{array}{l}\text { SGRQ-symptoms } \\
r_{s}(p \text {-value })\end{array}$ & $\begin{array}{l}\text { SGRQ-activity } \\
r_{s}(p \text {-value })\end{array}$ & $\begin{array}{l}\text { SGRQ-impact } \\
r_{s}(p \text {-value })\end{array}$ & $\begin{array}{l}\text { SGRQ-total } \\
r_{s}(p \text {-value })\end{array}$ \\
\hline Mobility & $0.135(0.032)$ & $0.140(0.026)$ & $0.158(0.012)$ & $0.148(0.012)$ \\
Self-care & $0.229(<0.001)$ & $0.136(0.031)$ & $0.247(<0.001)$ & $0.249(<0.001)$ \\
Usual activities & $0.214(0.001)$ & $0.178(0.005)$ & $0.233(<0.001)$ & $0.227(<0.001)$ \\
Pain/discomfort & $0.268(<0.001)$ & $0.133(0.034)$ & $0.195(0.002)$ & $0.237(<0.001)$ \\
Anxiety/depression & $0.440(<0.001)$ & $0.173(0.006)$ & $0.291(<0.001)$ & $0.341(<0.001)$ \\
EQ5D-VAS & $-0.349(<0.001)$ & $-0.071(0.262)$ & $-0.196(0.002)$ & $-0.236(<0.001)$ \\
\hline
\end{tabular}

$r_{s}=$ Spearman's rank correlation coefficient
2014). In this study, more than half of the participants had severe COPD and participants, on average, had been diagnosed with COPD for 7 years. The advanced nature and severity of the disease and associated prolonged suffering could have influenced this moderate correlation. Another study investigated the correlation between the EQ5D index score and the SGRQ-total score in patients with advanced COPD in the Netherlands (Wilke et al. 2012). This study showed a strong correlation between the EQ5D index score and the SGRQ-total score at baseline and moderate correlation at 4,8 and 12 months. However, the study did not report any correlation between the EQ5D dimensions/VAS and SGRQ domains. Therefore, the study results are not comparable with our study.

Ours is the first study to investigate the correlation between the health-related quality of life and respiratory health status of coal-based sponge iron plant workers. Our study proves that respiratory health status could be a potential predictor of health-related quality of life among coal-based sponge iron plant workers and vice versa. As they are related, a single intervention could be developed, evaluated and implemented to improve their health-related quality of life as well as their respiratory health status.

This study has some limitations that could restrict the generalisability of our results. First, the study was conducted among coal-based sponge iron factory workers in a particular location and it remains unknown whether similar significant relationships would be observed among coal-based sponge iron factory workers in other parts of India or worldwide. Second, it was not possible to determine the relationship between health-related quality of life and respiratory health status over time, as this was a cross-sectional study. A longitudinal study is needed to evaluate such a relationship over time. Finally, all the participants were male; therefore, any gender-related differences in health-related quality of life and respiratory health status might not be reflected. Despite these limitations, this study contributes to the ongoing research on the health-related quality of life and respiratory health status among coal-based sponge iron factory workers.

\section{Conclusion}

In conclusion, significant correlations were found between all EQ5D dimensions and EQ5D-VAS and all SGRQ scores, except between EQ5D-VAS and SGRQ-activity. A range of correlations was found: moderate between EQ5D-anxiety/depression and SGRQ-symptom, EQ5D-VAS and SGRQ-symptom, and EQ5D-anxiety/depression and SGRQ-total, but weak between all the other factors.

Funding The study was funded by a grant from the Blacksmith Institute, USA.

\section{Compliance with ethical standards}

Conflict of interest None of the authors has any conflict of interest related to the publication of this manuscript.

Open Access This article is distributed under the terms of the Creative Commons Attribution 4.0 International License (http:// creativecommons.org/licenses/by/4.0/), which permits unrestricted use, distribution, and reproduction in any medium, provided you give appropriate credit to the original author(s) and the source, provide a link to the Creative Commons license, and indicate if changes were made.

\section{References}

Balcells E, Gea J, Ferrer J, Serra I, Orozco-Levi M, de Batlle J et al (2010) Factors affecting the relationship between psychological status and quality of life in COPD patients. Health Qual Life Outcomes 8:108

Centre for Science and Environment (CSE) (2011) Sponge iron industry: the regulatory challenge. CSE, New Delhi

Cerana Foundation (2006) Risk appraisal study: sponge iron plants, Raigarh district. Cerana Foundation, Hyderabad, India

Chatterjee S (2011) Source, dispersal and impacts of airborne pollutants: a case study of Mangalpur industrial complex, Raniganj. J Hum Ecol 35:195-201

Chattopadhyay K (2016) Prevalence and predictors of respiratory diseases among coal-based sponge iron plant workers: a crosssectional study in Barjora, India. Annals of Global Health. https:// doi.org/10.1016/j.aogh.2016.05.001

Chattopadhyay K, Chattopadhyay C, Kaltenthaler E (2014) Healthrelated quality-of-life of coal-based sponge iron plant workers in Barjora, India: a cross-sectional study. BMJ Open 4:e006047. https://doi.org/10.1136/bmjopen-2014-006047 
Chattopadhyay K, Chattopadhyay C, Kaltenthaler E (2015) Respiratory health status and its predictors: a cross-sectional study among coalbased sponge iron plant workers in Barjora, India. BMJ Open 5: e007084. https://doi.org/10.1136/bmjopen-2014-007084

Chen J, Wong CK, McGhee SM, Pang PK, Yu WC (2014) A comparison between the EQ-5D and the SF-6D in patients with chronic obstructive pulmonary disease (COPD). PLoS ONE [Electronic Resource] 9:e112389

Dyer C, Hill S, Stockley R, Sinclair A (1999) Quality of life in elderly subjects with a diagnostic label of asthma from general practice registers. Eur Respir J 14:39-45

Fayers P, Machin D (2007) Quality of life: the assessment, analysis and interpretation of patient-reported outcomes, 2nd edn. John Wiley and Sons, Chichester

Gizaw Z, Yifred B, Tadesse T (2016) Chronic respiratory symptoms and associated factors among cement factory workers in Dejen town, Amhara regional state, Ethiopia, 2015. Multidisciplinary Respiratory Medicine 11:13. https://doi.org/10.1186/s40248-016-0043-6

Indian Council of Medical Research (ICMR) (2006) CMR ethical guidelines for biomedical research on human participants. ICMR, Delhi

Institute of Medicine (2001) Crossing the quality chasm: a new health system for the 21st century. National Academies Press, Washington

Jones P (1995) Issues concerning health-related quality of life in COPD. Chest 107(5 Suppl):187-193

Jones PW, Quirk FH, Baveystock CM (1991) The St George's respiratory questionnaire. Respir Med 85:25-31. https://doi.org/10.1016/ S0954-6111(06)80166-6

Lai P, Christiani D (2013) Long term respiratory health effects in textile workers. Curr Opin Pulm Med 19:152-157. https://doi.org/10.1097/ MCP.0b013e32835cee9a
Patra H, Sahoo B, Mishra B (2012) Status of sponge iron plants in Orissa. Vasundhara, Bhubaneswar

Rabin R, Oemar M, Oppe M, EuroQol Group (1990) EQ-5D-5L user guide: basic information on how to use the EQ-5D-5L instrument, version 1.0. EuroQol Group, Rotterdam

Rachiotis G, Behrakis PK, Vasiliou M, Yfantopoulos J (2006) Quality of life and smoking among industrial workers in Greece. La Medicina del lavoro 97:44-50

Starkie HJ, Briggs AH, Chambers MG, Jones P (2011) Predicting EQ-5D values using the SGRQ. Value Health 14:354-360. https://doi.org/ 10.1016/j.jval.2010.09.011

StataCorp (2015) Stata statistical software: release 14. StataCorp LP, College Station

Taghavi S, Mokarami H, Nazifi M, Choobineh A, Marioryad H, Kujerdi M (2014) The influence of socio-demographic, health and workrelated factors on health-related quality of life among Iranian industrial workers. Heath 6:2250-2260

The EuroQol Group (1990) Euroqol - a new Facility for the Measurement of health-related quality-of-life. Health Policy 16:199-208

Wilke S, Janssen DJ, Wouters EF, Schols JM, Franssen FME, Spruit MA (2012) Correlations between disease-specific and generic health status questionnaires in patients with advanced COPD: a one-year observational study. Health Qual Life Outcomes 10:98-98. https://doi. org/10.1186/1477-7525-10-98

World Health Organization (WHO) (2001) International classification of functioning, disability and health: ICF. WHO, Geneva

Zhu CY, Wang JJ, Fu XH, Zhou ZH, Zhao J, Wang CX (2012) Correlates of Quality of Life in China Rural-Urban Female Migrate Workers. Qual Life Res 21 doi:https://doi.org/10.1007/s11136-011-9950-3 